\title{
Community structure and spatial distribution of benthic fauna in the Bellingshausen Sea (West Antarctica)
}

J. I. Saiz ${ }^{1}$ ， F. J. García ${ }^{2}$, M. E. Manjón-Cabeza ${ }^{3}$, J. Parapar ${ }^{4}$, A. PeñaCantero $^{5}$, T. Saucède ${ }^{6}$, J. S. Troncoso ${ }^{7}$, A. Ramos ${ }^{8}$

${ }^{1}$ Dpto. Zoología y BCA, Universidad del País Vasco/EHU, Apdo. 644, 48080 Bilbao, Spain e-mail: ji.saiz@ehu.es

${ }^{2}$ Dpto. Sistemas Físicos, Químicos y Naturales, Fac. Ciencias Experimentales, Universidad Pablo de Olavide, 41013 Sevilla, Spain

${ }^{3}$ Dpto. Biología Animal, Universidad de Málaga, Campus de Teatinos s/n, 29071 Málaga, Spain

${ }^{4}$ Dpto. Bioloxía Animal, Universidade da Coruña, 15008 A Coruña, Spain

5 Instituto Cavanilles de Biodiversidad y Biología Evolutiva, Universidad de Valencia/Fundación General Universidad de Valencia, Apdo. 22085, 46071 Valencia, Spain

${ }^{6}$ Biogéosciences, Université de Bourgogne, CNRS, 6 Boulevard Gabriel, 21000 Dijon, France

${ }^{7}$ Dpto. e Ecoloxía Bioloxía Animal, Universidade de Vigo, Campus Lagoas-Marcosende s/n, 36200 Vigo, Spain

${ }^{8}$ Instituto Español de Oceanografía, Punta del Apio, Apdo. 1552, 36200 Vigo, Spain

Polar Biology, May 2008, Volume 31, Issue 6, pp 735-743

Received: 20 July 2007 / Revised: 7 January 2008 / Accepted: 10 January 2008 / Published online: 14 February 2008

\section{Cite this article as:}

Saiz, J.I., García, F.J., Manjón-Cabeza, M.E. et al. Polar Biol (2008) 31: 735. doi:10.1007/s00300-008-0414-3

The final publication is available at Springer via http://dx.doi.org/10.1007/s00300-008-0414-3

\section{Abstract}

The structure and spatial distribution of the macrofauna community of the Bellingshausen Sea in the western sector of Antarctica was studied during the 'BENTART-06' oceanographic expedition. This is one of the least explored Antarctic seas. A total of 20 box cores were sampled at 11 stations ranging from 157 to 3,304 m depth, using an USNEL-type box corer (BC) dredge. Representatives of 25 higher taxa of invertebrates were collected. Deeper sampling sites were less rich in taxa (4-7 taxa), whereas the figures were higher at shallower sites (up to 17 taxa). Faunal density on the sea bottom revealed a horizontal spatial gradient from the western sites with extremely low figures $\left(90\right.$ indiv. $\left./ \mathrm{m}^{2}\right)$ towards the eastern ones with the highest figures $\left(1,360\right.$ indiv. $\left./ \mathrm{m}^{2}\right)$ close to the Antarctic Peninsula. Several abiotic factors 
(depth, redox, organic matter, carbonates and particle size of surficial sediments) were measured simultaneously on the sea floor to characterise the substrate preferences of the fauna. Positive correlations were found between the faunal distribution and a combination of depth, redox values, and organic matter content of sediments. This indicates decreasing availability of food in the deeper bottoms of the Bellingshausen Sea with a prevalence of depauperated bottoms dominated almost exclusively by a foraminiferans community.

Keywords

Abiotic factors; Abundance; Antarctica; Bellingshausen Sea; Macrobenthos; PRIMER

\section{Introduction}

The Antarctic sector corresponding to the Bellingshausen Sea (BS) is one of the most difficult areas for a research vessel to visit because of the prevalence of ice (Clarke and Johnston 2003) during most of the year. As a result, this area has been comparatively less studied than the Weddell and Ross Seas, where many countries have conducted vast programs of research during the past decades. The situation is even worse when we realise that the majority of the few studies conducted in this remote geographical area are other than benthic studies. One exception is the recent publication of two faunal works on fishes and molluscs from Matallanas and Olaso (2007) and Troncoso et al. (2007).

The BS constitutes a natural connection between the Weddell and Ross seas along both sides of the Antarctic Peninsula with obvious zoogeographical significance in the dispersion of species around the waters of the Antarctic continent and through the Scotia Arc; with this study we seek to help in remedying the scarcity of data by exploring general characteristics of the benthos of this remote Antarctic area by using well known standard benthos study methods.

Thus, the aims of the present study are: (1) to characterise the faunal assemblages present on the sea floor and (2) to identify environmental factors that may affect and/or determine the composition and spatial distribution of fauna.

\section{Materials and methods}

Field sampling

The sampling program was carried out aboard the RV 'Hespérides' during the cruise named 'BENTART-06' in January and February 2006. Stations are reported in Fig. 1, and station locations and depths are given in Table 1. Sediment samples were collected by means of an USNEL-type box corer (BC) with a maximum breakthrough of $60 \mathrm{~cm}$ and an effective sampling area of $0.25 \mathrm{~m}^{2}$. When possible, two duplicate samples per station were carried out, and a total of $20 \mathrm{BC}$ samples were collected from 11 different stations at water depths between 157 and 3,304 m (Fig. 1, Table 1). 


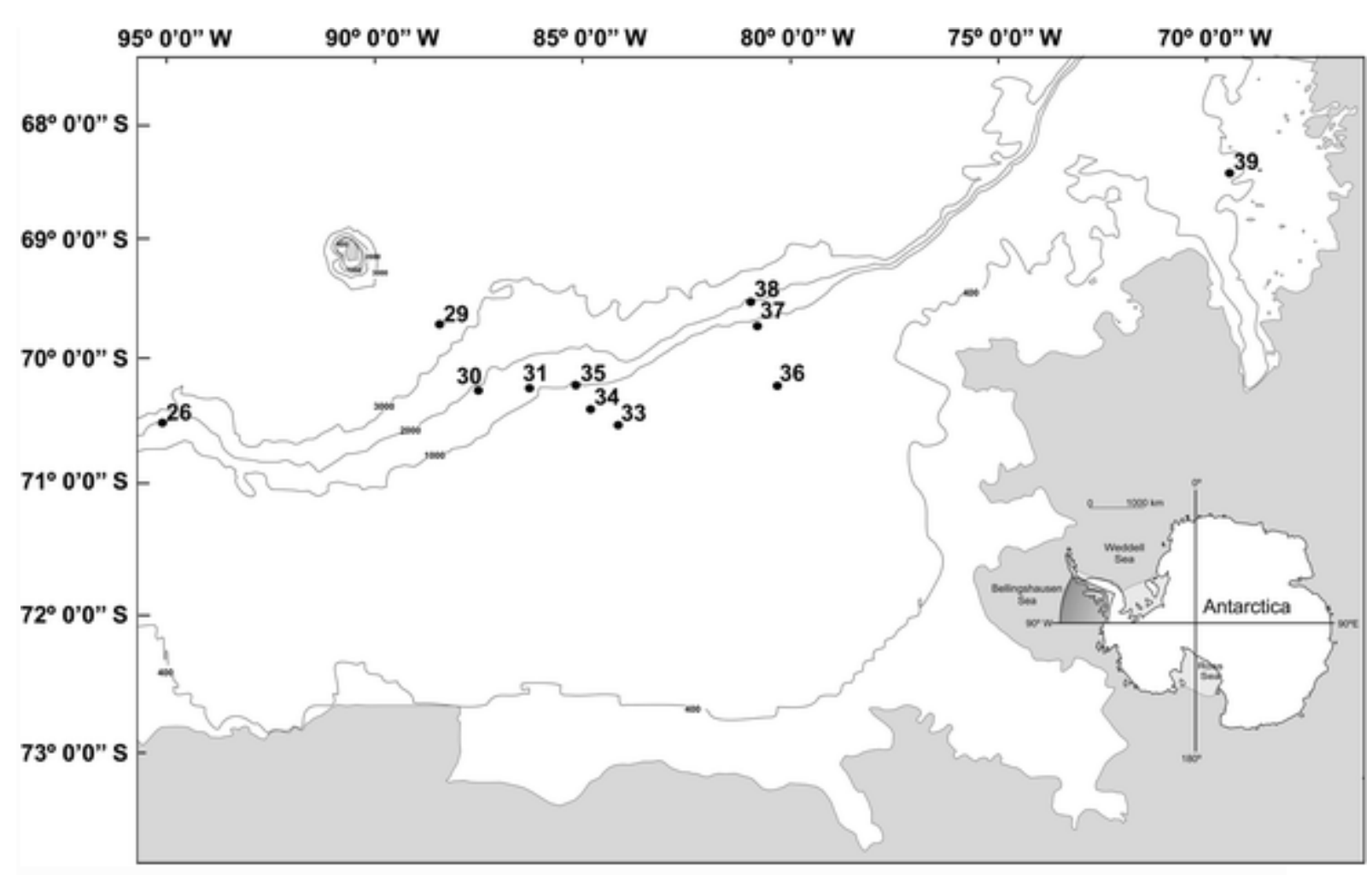

Fig. 1 Position of the stations sampled on the 'BENTART-06' cruise. The inset shows the Bellingshausen Sea (BS) location in Antarctica

At each station, the first BC sample was equally subdivided into four equal sub-samples of $0.063 \mathrm{~m}^{2}$. On the first sub-sample, temperature measurements and redox profiles (Eh) of sediment were performed immediately after sampling. Redox values (Eh) were measured with an Orion ORP 9678 electrode coupled to an Orion 3 Star Portable pH metre. A standard ORP solution (Orion 967861) was used as a reference. Subsequently, analyses of sediment granulometry, organic matter and carbonates' contents of the sediment were performed following the standard methods detailed in Eleftheriou and McIntyre (2005). Granulometric fractions were defined following Wentworth's classification system (Wentworth 1922): gravel (grain size $>2 \mathrm{~mm}$ ), coarse sand (grain size between 2 and $0.5 \mathrm{~mm}$ ), medium sand (grain size between 0.5 and $0.25 \mathrm{~mm}$ ), fine sand (grain size between 0.25 and $0.0625 \mathrm{~mm}$ ) and mud (grain size $<0.0625 \mathrm{~mm}$ ), and the respective percentages were noted. The carbonate content $\left(\mathrm{CO}_{3} \%\right)$ of the sediment was measured after treatment with hydrochloric acid, and the total organic matter content (OM\%) was estimated from the sediment weight loss after $4 \mathrm{~h}$ heating in an oven at $450^{\circ} \mathrm{C}$.

The other subsamples were used for quantitative assessment of the fauna present in the sediment. For each subsample, the sediment was sieved through three mesh sizes (5.0, 1.0 and $0.5 \mathrm{~mm}$ ) and the fauna collected was then sorted according to major taxonomic groups (Table 2). Finally, samples were preserved either in a buffered $4 \%$ formaldehyde seawater solution or in $70 \%$ ethanol for further identification analysis. 
Table 1 Station list with location and environmental parameters at the seafloor surface

\begin{tabular}{|c|c|c|c|c|c|c|c|c|c|c|c|}
\hline Station & Latitude (S) & Longitude (W) & Depth (m) & Eh & Organic matter $(\%)$ & Carbonate (\%) & Gravel (\%) & Coarse sand (\%) & Medium sand (\%) & Fine sand $(\%)$ & Mud (\%) \\
\hline 26 & $70^{\circ} 14^{\prime} 37^{\prime \prime}$ & $95^{\circ} 2^{\prime} 12^{\prime \prime}$ & 1,920 & 178.9 & 1.991 & 5.873 & 1.33 & 11.22 & 29.09 & 49.43 & 8.94 \\
\hline 29 & $69^{\circ} 26^{\prime} 5^{\prime \prime}$ & $88^{\circ} 26^{\prime} 10^{\prime \prime}$ & 3,304 & 262.1 & 8.916 & 1.143 & 1.54 & 5.56 & 2.47 & 5.25 & 85.19 \\
\hline 30 & $69^{\circ} 58^{\prime} 59^{\prime \prime}$ & $87^{\circ} 31^{\prime} 5^{\prime \prime}$ & 1,814 & 187.7 & 7.005 & 2.972 & 58.38 & 1.78 & 1.02 & 8.88 & 29.95 \\
\hline 31 & $69^{\circ} 56^{\prime} 59^{\prime \prime}$ & $86^{\circ} 19^{\prime} 16^{\prime \prime}$ & 1,426 & 207.8 & 5.310 & 2.539 & 0.00 & 2.22 & 4.81 & 20.74 & 72.22 \\
\hline 33 & $70^{\circ} 15^{\prime} 54^{\prime \prime}$ & $84^{\circ} 11^{\prime} 27^{\prime \prime}$ & 438 & 290.2 & 4.017 & 1.377 & 20.11 & 12.99 & 8.86 & 26.32 & 31.72 \\
\hline 34 & $70^{\circ} 8^{\prime} 12^{\prime \prime}$ & $84^{\circ} 51^{\prime} 41^{\prime \prime}$ & 603 & 326 & 1.799 & 1.267 & 0.00 & 12.91 & 14.98 & 59.89 & 12.21 \\
\hline 35 & $69^{\circ} 56^{\prime} 2^{\prime \prime}$ & $85^{\circ} 11^{\prime} 18^{\prime \prime}$ & 1,117 & 260.7 & 7.360 & 2.396 & 47.65 & 3.78 & 1.73 & 9.13 & 37.72 \\
\hline 36 & $69^{\circ} 56^{\prime} 17^{\prime \prime}$ & $80^{\circ} 24^{\prime} 33^{\prime \prime}$ & 560 & 289 & 8.507 & 0.465 & 33.15 & 1.08 & 1.08 & 3.96 & 60.72 \\
\hline 37 & $69^{\circ} 26^{\prime} 23^{\prime \prime}$ & $80^{\circ} 51^{\prime} 37^{\prime \prime}$ & 495 & 244 & 5.703 & 0.645 & 35.37 & 17.04 & 10.30 & 16.15 & 21.20 \\
\hline 38 & $69^{\circ} 14^{\prime} 5^{\prime \prime}$ & $80^{\circ} 61^{\prime} 12^{\prime \prime}$ & 1,324 & 298.2 & 5.981 & 0.828 & 65.69 & 3.14 & 1.26 & 2.72 & 27.20 \\
\hline 39 & $68^{\circ} 7^{\prime} 37^{\prime \prime}$ & $69^{\circ} 36^{\prime} 12^{\prime \prime}$ & 157 & 221.9 & & & & & & & \\
\hline
\end{tabular}

Gravel $(>2 \mathrm{~mm})$, coarse sand $(>0.5 \mathrm{~mm})$, medium sand $(>0.25 \mathrm{~mm})$, fine sand $(>0.0625 \mathrm{~mm})$, mud $(<0.0625 \mathrm{~mm})$ 
Table 2 Taxa abundance per square metre detected on the 'BENTART-06' cruise

\begin{tabular}{|c|c|c|c|c|c|c|c|c|c|c|c|c|c|c|c|c|c|c|c|c|}
\hline & 26.1 & 26.2 & 29 & 30.1 & 30.2 & 31.1 & 31.2 & 33 & 34.1 & 34.2 & 35.1 & 35.2 & 36.1 & 36.2 & 37.1 & 37.2 & 38.1 & 38.2 & 39.1 & 39.2 \\
\hline Amphipoda & & & & & & & 16 & & 8 & 96 & 16 & 48 & & & 8 & 16 & & & 16 & \\
\hline Anthozoa & & & & & & 8 & & & & & & & & & & & & & & 16 \\
\hline Ascidiacea & 8 & & 16 & & & & & & 8 & & & & & & & & & & 8 & 16 \\
\hline Asteroidea & 8 & & 16 & & & & & & 8 & & & & & & & & & & 8 & 16 \\
\hline Bivalvia & & & & 56 & 16 & 16 & 32 & & & & 16 & 16 & 8 & & & 32 & 16 & 16 & 56 & \\
\hline Brachiopoda & & & & & & 8 & & 128 & & & & 48 & & & 72 & 16 & 56 & & & \\
\hline Bryozoa & & & 16 & & & 8 & 112 & 80 & 40 & & 56 & 128 & 32 & 16 & 160 & 160 & 16 & 64 & 168 & 496 \\
\hline Cumacea & & 8 & 16 & & & & & & & & & & & & & & & & & \\
\hline Echinoidea & 8 & & 16 & 16 & & 24 & & 32 & 8 & & & & & & 32 & & 8 & & & \\
\hline Foraminifera & 88 & 64 & 480 & 1,096 & 480 & 872 & & 576 & 136 & 304 & 160 & 192 & 520 & 752 & 96 & 80 & 432 & 32 & 32 & \\
\hline Gastropoda & & & & & & & & & & & & & 8 & & & 16 & & & 96 & 32 \\
\hline Holothuroidea & & & & & & & & 32 & & & & & & & & & & & 24 & 16 \\
\hline Hydrozoa & & & & & & & & & 16 & & & & & & & & & & & 16 \\
\hline Isopoda & & & & & & & & & 8 & 16 & & & & & & & & & & \\
\hline Mysidacea & & & & & & & & & & & & & & & & & 8 & & & \\
\hline Nematoda & & & & & & & & & & & & & & & & & 8 & & & \\
\hline Nemertea & & & 16 & & & & & & 16 & & & & & & & & 8 & & 16 & 16 \\
\hline Ophiuroidea & & & & & & 8 & 48 & 48 & 16 & 64 & 8 & & 32 & & 48 & 64 & 32 & 48 & 48 & 16 \\
\hline Pycnogonida & & & & & & & & & & & & & & & & & & & 8 & 64 \\
\hline Pterobranchia & & & & & & & & & & & & & & & & & & & 400 & \\
\hline Polychaeta & 24 & 8 & 16 & 8 & & 8 & 80 & 80 & 128 & 48 & 8 & & 136 & 96 & 48 & 32 & 72 & & 568 & 336 \\
\hline Polyplacophora & & & & & & & 16 & & & & & & & & 8 & 32 & & & 16 & \\
\hline Porifera & & & & & & & & & & & & & 8 & & & & & & 24 & 64 \\
\hline Scaphopoda & & & & & & 16 & & & & & 16 & & 16 & 32 & & & 8 & & 16 & \\
\hline Sipuncula & & & & & & 8 & & & 16 & 32 & & & & & & & 8 & & & \\
\hline Total & 128 & 80 & 576 & 1,176 & 496 & 976 & 304 & 992 & 400 & 560 & 280 & 432 & 768 & 896 & 472 & 448 & 672 & 160 & 1,496 & 1,088 \\
\hline
\end{tabular}


Data analysis

Data were organised with each station by taxa matrices (Table 2). Univariate measurements such as total abundance $(N)$ and number of taxa $(T)$ were calculated for each sampling station (Table 3). The composition of macrobenthic assemblages was analysed by means of nonparametric multivariate techniques as described by Field et al. (1982) using the PRIMER v 5.0 (Plymouth Routines in Multivariate Ecological Research) software package (Clarke and Gorley 2001). A matrix of similarity between samples was constructed by means of the BrayCurtis similarity coefficient by first applying fourth root transformation on abundance figures to down-weight the contribution of the most abundant taxa. From this matrix the 20 box-core samples were classified by cluster analysis based on the group-average sorting algorithm, as well as an ordination analysis was performed by means of a non-metrical multidimensional scaling (MDS). The SIMPER routine was then used to identify taxa that contributed greatly to distinctions between station groups.

Table 3 Figures for number of taxa $(T)$ and abundance

$(N)$ over all the sampling sites investigated on the 'BENTART-06' cruise

\begin{tabular}{lll}
\hline Site & $\mathbf{T}$ & $\mathbf{N}$ \\
\hline 26 & 5 & 91 \\
29 & 7 & 288 \\
30 & 4 & 949 \\
31 & 12 & 752 \\
33 & 8 & 496 \\
34 & 11 & 453 \\
35 & 8 & 331 \\
36 & 9 & 811 \\
37 & 10 & 464 \\
38 & 12 & 501 \\
39 & 17 & 1,360 \\
\hline
\end{tabular}

Investigations into the environmental factors having a potential influence on the macrobenthic distribution were carried out using the BIO-ENV routine (Clarke and Ainsworth 1993) of PRIMER package and canonical correspondence analysis (CCA) using the CANOCO (v. 3.10) and CanoDraw (v. 3.0) programs of ter Braak $(1988,1990)$ and Smilauer (1992), respectively. Specifically, depth (m) and the following abiotic variables were used in the analyses: redox state (Eh) of sediments, organic matter content (OM) (as \%), different granulometric fractions and carbonate content (\%). All these abiotic variables were standardised prior to analysis. Principal component analysis (PCA) was performed to reduce the number of autocorrelated environmental variables.

\section{Results}

Abundance, taxa richness and diversity

About 6,496 individuals belonging to 25 major taxa were collected (Table 2). The lowest abundance value was recorded at station $26\left(91\right.$ indiv. $\left./ \mathrm{m}^{2}\right)$, at a depth of $1,920 \mathrm{~m}$ (located at the western part of BS); while the highest was recorded at station $39\left(1,360\right.$ indiv. $\left./ \mathrm{m}^{2}\right)$, at $157 \mathrm{~m}$ deep at Margarite Bay (eastern area); this was due to the abundance of sedentary Polychaeta (432 indiv. $/ \mathrm{m}^{2}$ ) and Pterobranchia (267 indiv. $/ \mathrm{m}^{2}$ ) (Fig. 2). Taxa richness ranged from 4 (station 30) to 17 (station 39). 


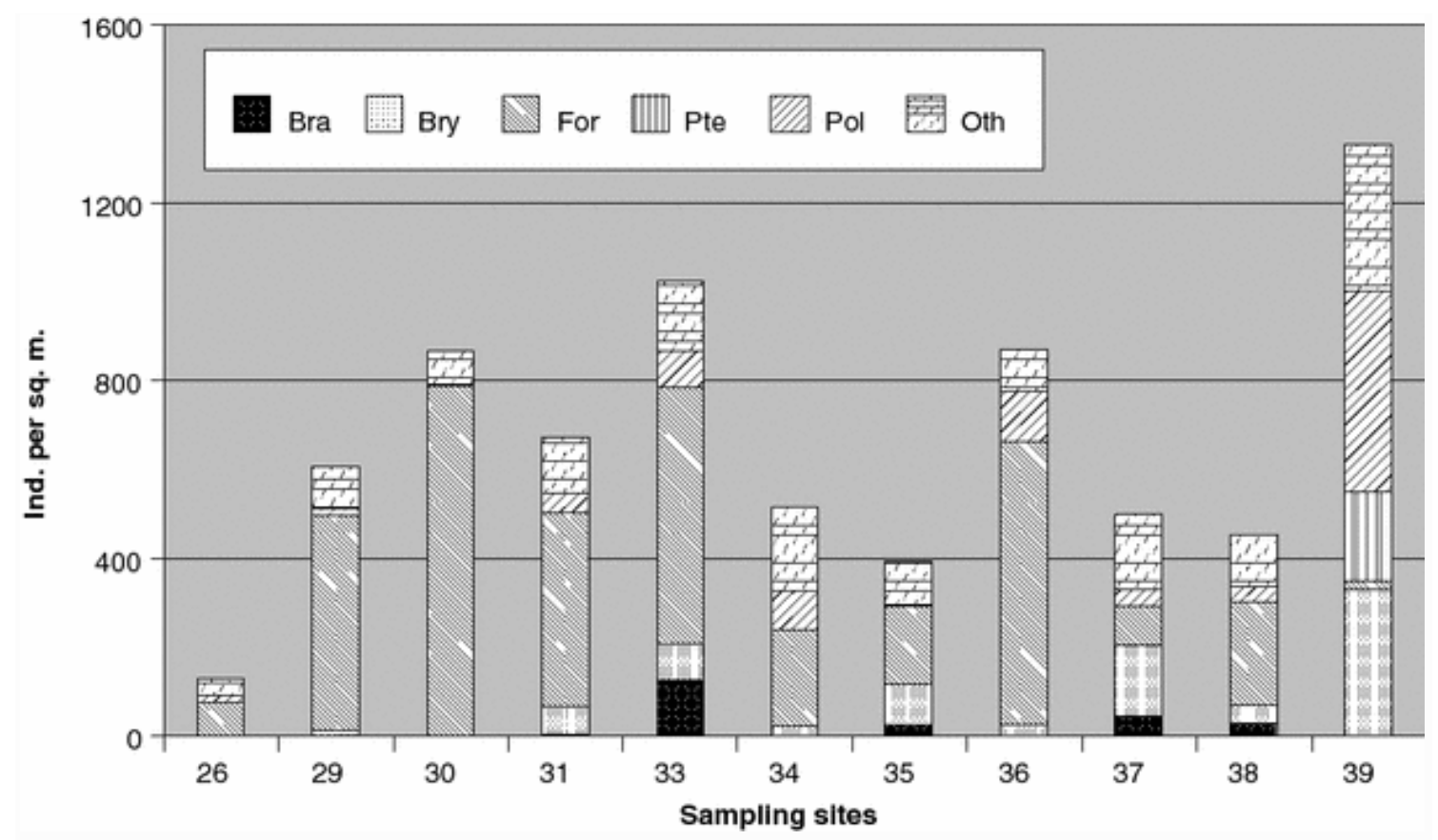

Fig. 2 Taxonomic composition of benthic fauna from box-core samples taken in the Bellingshausen Sea. An average was estimated for each sampling site when available. Acronyms: Bra brachiopods, Bry bryozoans, For foraminiferans; Pte pterobranchs; Polpolychaetes; Ot $h$ others

Benthic assemblages

Cluster analysis (Fig. 3) shows that stations can be placed together into three main groups with a similarity level of 50\%. Group BS1 includes three deep-water stations (between 1,814 and 3,304 $\mathrm{m}$ in depth) located in the western sector of BS with bottoms that show a high percentage of carbonates. Group BS2 comprises eight shallow and mid-water stations (157$1,426 \mathrm{~m}$ deep) with medium levels of mud and low percentages of carbonates. The MDS ordination plot (Fig. 4) shows similar results to those of the dendrogram, with an acceptable stress value (0.14). Sampling sites are segregated along the first dimension which can be easily identified as a depth gradient from deeper stations off the western sector of the BS to the eastern shallow water stations closer to the Antarctic Peninsula. In fact, a Spearman rank correlation of depth and MDS $x$-axis co-ordinates (a one-dimensional measure of taxa change) gave a coefficient of $0.79(P<0.01)$. The dispersion of sampling sites along the vertical MDS axis being distinctly less well pronounced, was negatively correlated with the recorded redox values of surficial sediments $(\rho=-0.6)$, although lacking significance $(P=0.07)$. 
Fig. 3 Hierarchical cluster analysis (square root transformed density data, Bray-Curtis similarity coefficient). Two main clusters are delineated, besides site 39 used as reference. $B S 1=$ deeper sampling sites and $B S 2=$ mid and shallower ones (remaining stations)

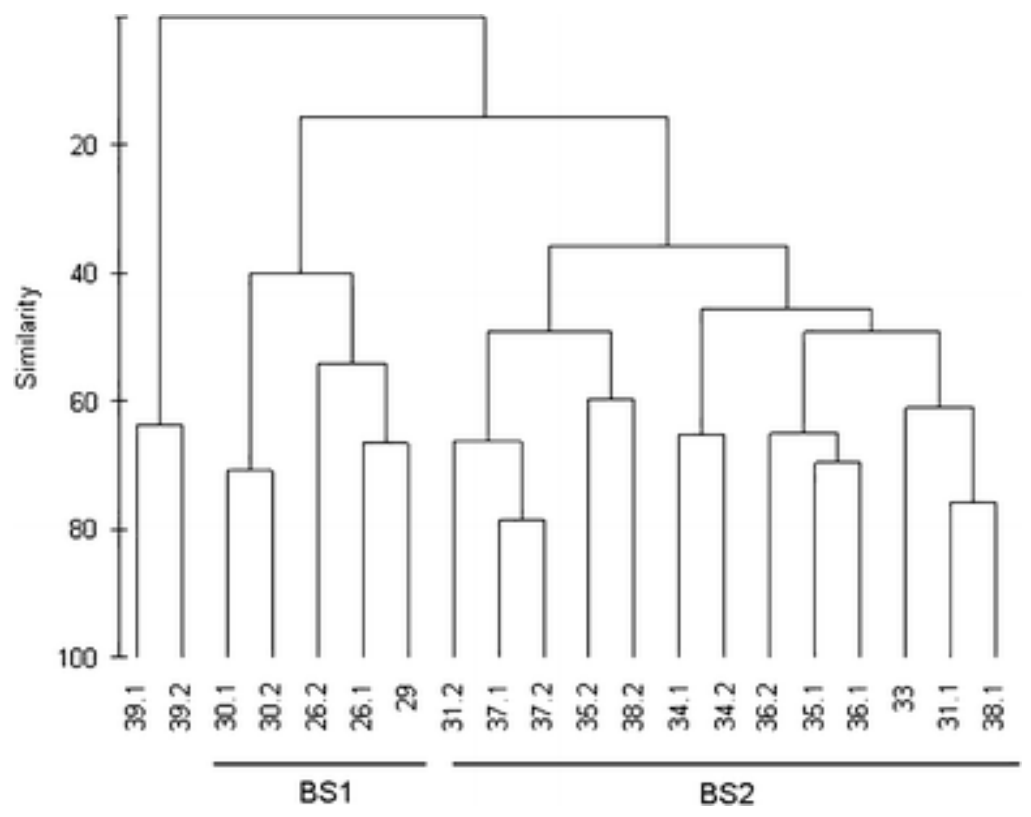

Fig. 4 MDS plot illustrating a deep-shallow water gradient across the Bellingshausen Sea

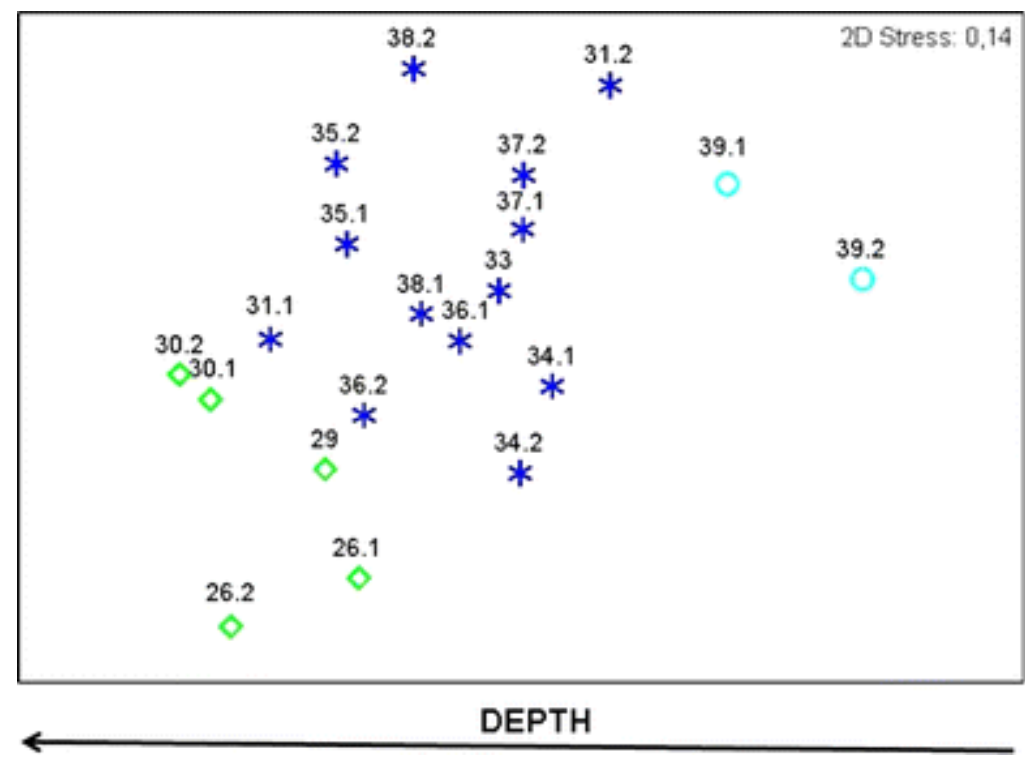

The results of the SIMPER analysis for the similarity of groups BS1 and BS2 are shown in Table 4. Foraminifera, Bryozoa, Polychaeta and Ophiuroidea account for almost $80 \%$ of the dissimilarity level between deeper-water group BS1 and the mid-water and shallower stations of group BS2. In short (see Fig. 5), deeper sampling sites (BS1) are dominated almost exclusively by Foraminifera, whereas mid-water sites (BS2) exhibit further coverage of bryozoan colonies over drop stones and also a superficial film of small Polychaeta. It is quite evident that BS2 sampling sites show a more characteristic balance between microfauna and macrofauna (Fig. 5). 
Table 4 Results of SIMPER analysis

\begin{tabular}{|c|c|c|c|c|c|c|}
\hline & Av. abund. & Av. sim. & \multicolumn{2}{|c|}{ Sim./SD } & Contrib. (\%) & Cum. (\%) \\
\hline \multicolumn{7}{|c|}{ Group BS 1 (av. sim.: 41.2\%) } \\
\hline Foraminifera & 441.60 & 38.19 & 1.47 & \multicolumn{2}{|c|}{92.71} & 92.71 \\
\hline \multicolumn{7}{|c|}{ Group BS 2 (av. sim.: 48.3\%) } \\
\hline Foraminifera & 319.38 & 23.74 & 1.25 & \multicolumn{2}{|c|}{53.89} & 53.89 \\
\hline Bryozoa & 67.08 & 7.76 & 0.84 & \multicolumn{2}{|c|}{17.60} & 71.49 \\
\hline \multirow[t]{2}{*}{ Polychaeta } & 56.62 & 4.94 & 0.90 & \multicolumn{2}{|c|}{11.21} & 82.70 \\
\hline & $\begin{array}{l}\text { Av. } \\
\text { abund. } \\
\text { (BS 1) }\end{array}$ & $\begin{array}{l}\text { Av. } \\
\text { abund. } \\
\text { (BS 2) }\end{array}$ & $\begin{array}{l}\text { Av. diss. } \\
\text { (BS } 1 \text { and } \\
\text { BS 2) }\end{array}$ & Diss./SD & $\begin{array}{l}\text { Contrib. } \\
(\%)\end{array}$ & Cum. (\%) \\
\hline \multicolumn{7}{|c|}{ MB1 and MB2 (av. dissimil.: 64.11\%) } \\
\hline Foraminifera & 441.6 & 319.38 & 34.05 & 1.53 & 53.11 & 53.11 \\
\hline Bryozoa & 3.2 & 67.08 & 8.61 & 0.95 & 13.43 & 66.53 \\
\hline Polychaeta & 11.2 & 56.62 & 5.47 & 1.07 & 8.54 & 75.07 \\
\hline Ophiuroidea & 0.0 & 32.00 & 4.05 & 0.97 & 6.32 & 81.39 \\
\hline
\end{tabular}

Taxa are ranked according to their average contribution to similarity within (top tables) or between (down table) assemblages BS 1 and BS 2. Average abundances, ratio (similarity or dissimilarity/standard deviation, Sim./SD), and percentage of cumulative similarity are also included. A cut-off at a cumulative $\%$ dissimilarity of $80 \%$ was applied

Fig. 5 Taxa composition at two main station groups as defined by cluster analyses. Abbrev.: $B S$ 1: deeper sites group (top); BS 2: shallower sites group (bottom); Acronyms: FORForaminifera, $B$ $R Y O$ Bryozoa, POL Polychaeta, OPHIU Ophiuroidea

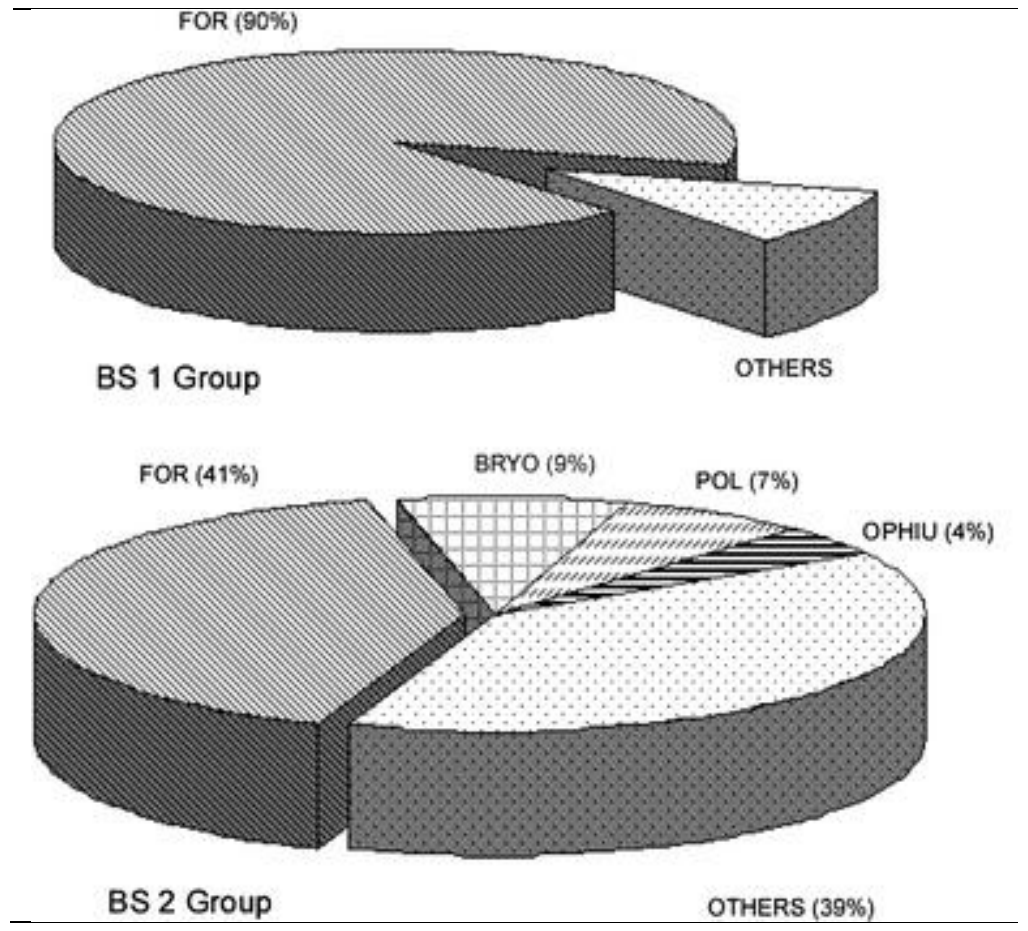

Relationship between biotic and environmental variables

Sediment samples collected across the BS encompass bottoms that lie between the sublittoral and bathyal zones (157-3,304 m deep). Sediments are mainly composed of gravels and mud, with a medium organic matter content (Table 1). Superficial sediments appear to be oxidised, 
as shown by redox (Eh) values in excess of $178.9 \mathrm{mV}$. In most stations, the carbonate content of sediments is relatively low.

The BIO-ENV procedure (Table 5) shows that the best combination of environmental variables with the highest correlation with the faunistic data recorded ( $\rho w: 0.502)$ is a combination of water depth, Eh values and OM of the sediments. Particularly, depth is the variable matching the best result when each abiotic variable is considered separately ( $\rho w$ : $0.317)$.

Table 5 Result of BIOENV analysis to select the number of abiotic variables which best matches the biotic matrix

\begin{tabular}{|c|c|c|}
\hline $\begin{array}{ll}\text { Number } & \text { of } \\
\text { variables }\end{array}$ & Correlation & Selections \\
\hline 1 & 0.317 & 1 \\
\hline 1 & 0.305 & 2 \\
\hline 1 & 0.298 & 4 \\
\hline 1 & 0.237 & 3 \\
\hline 2 & 0.423 & 1,2 \\
\hline 2 & 0.390 & 2,9 \\
\hline 2 & 0.384 & 1,4 \\
\hline 2 & 0.380 & 1,7 \\
\hline 3 & 0.502 & $1-3$ \\
\hline 3 & 0.464 & $1,2,9$ \\
\hline 3 & 0.458 & $1,3,4$ \\
\hline 3 & 0.454 & $1,2,7$ \\
\hline 4 & 0.487 & $1-4$ \\
\hline 4 & 0.480 & $1-3,9$ \\
\hline 4 & 0.468 & $1,2,4,9$ \\
\hline 5 & 0.494 & $1-4,9$ \\
\hline 5 & 0.464 & $1,2,4,7,9$ \\
\hline 5 & 0.453 & $1-4,7$ \\
\hline
\end{tabular}

A preliminary principal component analysis (PCA) of the environmental variables of Table lindicated that, for the sampling area, several fractions of 'sand' were highly autocorrelated with 'gravel' and ' $\mathrm{CO}_{3}$ ' content of sediments. Consequently, they were considered 'redundant' and discarded for further ordination analysis. The ordination diagram (CCA) (Fig. 6) of the first two axes reveals the general relationships between faunal distribution on the sea-floor and the revised sub-set of environmental variables sampled in the field (sand fractions removed). Eigenvalues of the CCA are $\lambda_{1}=0.24$ and $\lambda_{2}=0.19$ for the two first axes. Both axes capture $41.5 \%$ of the cumulative variance of the macrobenthic data and $62.3 \%$ of the variance in the faunal-environment relationship (Table 6). The importance of the variables depth and redox is again shown by long vectors in the CCA plot (Fig. 6). OM is negatively correlated with redox, whereas $\mathrm{CO}_{3}$ is relatively correlated with depth. The results reflect the sampling scheme, because most of the deepest sites (corresponding to cluster BS1 in Fig. 3) had their distribution optima along the depth gradient. Sampling sites 33, 34, and 36, positioned in the lower part of the diagram (Fig. 6), presented high redox values on the sediment surface. The remaining stations positioned to the upper left part of the CCA plot (Fig. 6) were moderately affected either by high deposits of gravel (stations 35, 37 and 38 ) or mud (station 31) at the sediment surface. 
Fig. 6 Canonical

correspondence analysis

(CCA) ordination showing

sampling sites and a selection

of environmental variables

relative to axes I and II

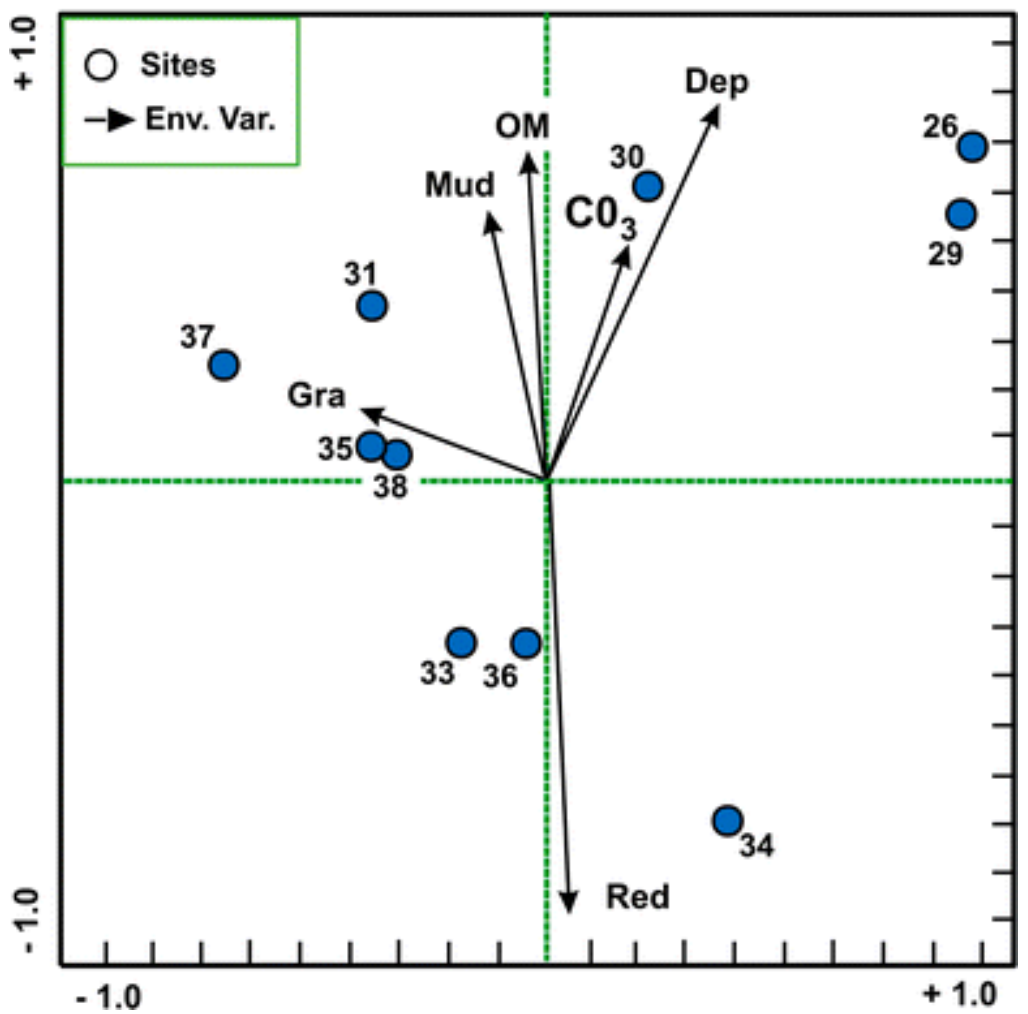

Table 6 Summary statistics for the first four axes of Canonical Correspondence Analysis (CCA)

\begin{tabular}{llllll}
\hline Axes & I & II & III & IV & Total inertia \\
\hline Eigenvalues & 0.236 & 0.187 & 0.104 & 0.082 & 1.019 \\
$\begin{array}{l}\text { Species-environment correlations } \\
\begin{array}{l}\text { Cumulative percentage variance } \\
\text { of species data }\end{array}\end{array}$ & 0.980 & 0.959 & 0.966 & 0.046 & \\
$\begin{array}{l}\text { of species-environment relation } \\
\text { Sum of all unconstrained eigenvalues }\end{array}$ & 34.8 & 61.5 & 51.7 & 59.7 & \\
Sum of all canonical eigenvalues & & & 77.6 & 89.6 & \\
\hline
\end{tabular}

\section{Discussion}

The decrease in the supply of organic matter as depth increases has long been considered the main limiting factor for the Antarctic benthos (Knox 1994; Arntz et al. 1994), which generally receives limited organic inputs of low nutritional quality at deeper bottoms (Piepenburg et al. 2002; Smith et al. 2006). We observed extreme differences in taxa richness and faunal densities over the area investigated. The high values of both faunal descriptors recorded at station 39 are probably a benthic response to the shallower depth of a sampling site which is located at the eastern border of the BS, close to the Antarctic Peninsula. Hence, this location may be considered as a control or reference situation of a 'typical' Antarctic benthos as characterised in previous papers by our team (Saiz-Salinas et al. 1997, 1998) with an average abundance of $1,236 \mathrm{indiv} . / \mathrm{m}^{2}$. In fact, the figures recorded (taxa $=17$ and density $=1,360$ indiv. $/ \mathrm{m}^{2}$ ) in our study lie within the ranges previously compiled in the relevant literature by Jazdzewski et al. (1986), Mühlenhardt-Siegel (1988), Gerdes et al. (1992), Knox (1994) and Gambi et al. (1994) at similar depths. By contrast, the average figure 
for the BS shows (taxa $=9$ and density $=493$ indiv. $/ \mathrm{m}^{2}$ ) lower abundances withremarkably-even lower figures at deeper bottoms $\left(\right.$ taxa $=4$; density $=90$ indiv. $\left./ \mathrm{m}^{2}\right)$. In general, the benthic response of the seabed of the BS is quite poor, indicating the existence of a vast 'benthic desert' driven by an oligotrophic regime (Mouriño, personal communication), a situation which is exacerbated still further by the influence of physical disturbances (such as iceberg scouring) and depth.

Considering abundance and richness levels of individual taxa, variations between the main clusters of stations detected in the multivariate analysis reveal two contrasting faunal strategies that are well illustrated in Fig. 5. Deeper sites (cluster BS1) show an exclusive dominance of foraminiferans (accounting for proportions of 90\%) with correspondingly low biodiversity levels of other organisms. Similar observations have been reported in other polar studies (Wollenburg and Kuhnt 2000; Schewe and Soltwedel 2003) with a rapid reaction of foraminiferans species to the pulsed deposition of food particles from superficial waters onto the seabed. It is precisely the short reproduction cycles of Foraminifera that enable them to react rapidly to changing environmental conditions that favour opportunistic species capable of rapidly exploiting organic supplies deposited at the seafloor (Schewe and Soltwedel 2003). This should be considered in our opinion as an indication of the first steps in an ecological succession from barren sediments towards microfauna dominance led by pioneering opportunists, such as Foraminifera. In fact, sediment cores on board the vessel showed no traces of bioturbation, which may indicate negative effects by physical disturbances during the austral summer under conditions of low availability of food.

By contrast, shallower sites (cluster BS2) show a greater heterogeneity of taxa, because Foraminifera shares its ecological dominance with an infauna of deposit-feeding Polychaeta and an epifauna of encrusting Bryozoa over pebbles and stones. In this case, sediment cores show a few burrows and many drop-stones over the surface coming from icebergs, with a rich encrusting fauna of small colonies of bryozoans. The abundance of bryozoans varies from 26 to 277 colonies $/ \mathrm{m}^{2}$ throughout the sampling sites of cluster BS2. It has been suggested elsewhere that the availability of a hard substratum limits the abundance and diversity of bryozoans on the Hebridean continental slope (Hughes 2001). This author also notes that the small average size of the individual rocks severely limits the space available for subsequent growth and probably accounts for the prevalence of spot colony forms as observed in our survey. By contrast, Oschmann (1990) relates the low spatial coverage of epifauna on dropstones from the Norwegian Sea to seasonal food scarcity as a factor limiting community development. At this stage it is difficult to decide which is the most prevalent limiting factor (trophic ecology or physical disturbance, or even a combination of the two) responsible for the wide variation and size of bryozoan colonies on dropstones in the BS.

On the other hand, the multivariate plots (Figs. 3, 4) also show a neat west-east gradient with taxa richness levels increasing towards the east where the Antarctic Peninsula lies. Taxa richness, which is an easy 'surrogate' for diversity, is negatively influenced by catastrophic disturbances derived from more intense iceberg traffic in the western area of the BS. In this sense, Hillenbrand et al. (2003) recently noted a prevalence of foraminiferal deposits in the western part of the BS, whereas the eastern area is characterised by diatom-bearing and carbonate-free sediments. Moreover, they relate the sedimentary differences with opposite modes of biological production driven by contrasting oceanographic regimes. These 
differences drastically affect faunal assemblages on the sea floor as recorded by our own results.

Plausible alternative explanations can be offered for all the environmental variables best correlated with the multivariate spatial pattern detected throughout the BS. Depth, redox values and carbonates achieve the highest correlation values on their own ( $\rho w \geq 0.3)$. The separate effects of abiotic variables on biota distribution are improved more by a synergy of depth, redox values and OM content of the sediments $(\rho w>0.5)$, as shown by the BIO-ENV analysis. In energy-limited systems such as deep sea or polar waters, food supply has repeatedly been proposed as the prime agent controlling macrofauna on the seafloor (Piepenburg et al. 2002). But the improvement recorded in the final result of the BIO-ENV introduced by the redox state of the sediments might indicate a role for microorganisms in converting refractory OM into better-quality food for the benthos as noted by Kröncke et al. (2000) in the Arctic.

As both the BIO-ENV procedure and CCA analysis separately identified 'depth', 'redox' and (to a lesser extent) ' $\mathrm{OM}$ ' as the major environmental variables influencing the faunal distribution along the BS, the results obtained with two different statistical techniques can be viewed with a reasonable degree of confidence.

Other physical disturbances, not sampled by our survey and linked to intense iceberg traffic from the mainland (such as iceberg scouring over the sea-floor, high sedimentation rates and intense fall of drop-stones onto the sea-floor), were continuously observed; at least we were able to trace expected responses of the benthos with water depth and food quality, as shown in other general studies (Graf 1992; Piepenburg et al. 2002).

In short, the exploratory expedition 'BENTART-06' provided a glimpse into this understudied Pacific sector of Antarctica. While the limited sample size does not enable broad conclusions to be drawn at this point, our results suggest a trend of faunal abundance decreasing with water depth, which is well established for other oceanic regions. This trend is most likely linked to limited low-quality food availability for the deep-sea benthos. The results also suggest a neat west-east spatial diversity gradient across the BS, with numbers of taxa increasing towards the east in accordance with the recent sedimentary analyses published by Hillenbrand et al. (2003). Nevertheless, a more comprehensive study of the fauna in the BS is needed to provide a complete faunal inventory and a better understanding of other ecological processes, especially before drastic changes occur in Antarctica due to global warming.

\section{Acknowledgments}

The 'BENTART-06' cruise was funded by the Antarctic Programme GLC2004-01856/ANT of the Spanish Government. We would like to express our thanks to the crew and UTM technicians of R/V 'Hespérides', who helped in the collection of samples. 


\section{References}

Arntz WE, Brey T, Gallardo VA (1994) Antarctic zoobenthos. Oceanogr Mar Biol Annu Rev 32:241-304

Clarke KR, Ainsworth M (1993) A method of linking multivariate community structure to environmental variables. Mar Ecol Prog Ser 92:205-219

Clarke KR, Gorley RN (2001) PRIMER (Plymouth Routines In Multivariate Ecological Research) v5: User manual/tutorial, pp 1-91 (PRIMER-E Ltd, Plymouth)

Clarke A, Johnston NM (2003) Antarctic Marine Benthic diversity. Oceanogr Mar Biol Annu Rev 41:47-114

Eleftheriou A, McIntyre A (2005) Methods for the study of marine benthos. Blackwell, Oxford

Field JG, Clarke KR, Warwick RM (1982) A practical strategy for analysis multispecies distribution patterns. Mar Ecol Prog Ser 46:7-12

Gambi MC, Lorenti M, Russo GF, Scipione MB (1994) Benthic associations of the shallow hard bottoms off Terra Nova Bay, Ross Sea: zonation, biomass and population structure. Antarct Sci 6:449-462

Gerdes D, Klages M, Arntz WE, Herman RL, Galeron J, Hain S (1992) Quantitative investigations on macrobenthos communities of the southeastern Weddell Sea shelf based on multibox corer samples. Polar Biol 12:291-301

Graf G (1992) Benthic-pelagic coupling: a benthic view. Oceanogr Mar Biol Annu Rev 30:149190

Hillenbrand C-D, Grobe H, Diekmann B, Kuhn G, Futterer DK (2003) Distribution of clay minerals and proxies for productivity in surface sediments of the Bellingshausen and Amundsen seas (West Antarctica). Relation to modern environmental conditions. Mar Geol 193:253-271

Hughes DJ (2001) Quantitative analysis of a deep-water bryozoan collection from the Hebridean continental slope. J Mar Biol Assoc UK 81:987-993

Jazdzewski K, Jurasz W, Kittel W, Premier E, Presier P, Sicinski J (1986) Abundance and biomass estimates of the benthic fauna in Admiralty Bay, King George Island, South Shetland Islands. Polar Biol 6:5-16

Knox GA (1994) The biology of the Southern Ocean. Cambridge University Press, Cambridge

Kröncke I, Vanreusel A, Vincx M, Wollenburg J, Mackensen A, Liebezeit G, Behrends B (2000) Different benthic size compartments and their relation to sediment chemistry in the deep Eurasian Arctic Ocean. Mar Ecol Prog Ser 199:31-41

Matallanas J, Olaso I (2007) Fishes of the Bellingshausen Sea and Peter I Island. Polar Biol 30:333-341

Mühlenhardt-Siegel U (1988) Some results on quantitative investigations of macrozoobenthos in the Scotia Arc (Antarctica). Polar Biol 8:241-248

Oschmann W (1990) Dropstones-rocky mini-islands in high latitude pelagic soft substrate environments. Senckenberg Marit 21:55-75

Piepenburg D, Schmid MK, Gerdes D (2002) The benthos off King George Island (South Shetland Islands, Antarctica): further evidence for a lack of latitudinal biomass cline in the Southern Ocean. Polar Biol 25:146-158

Saiz-Salinas JI, Ramos A, García FJ, Troncoso JS, San Martín G, Sanz C, Palacín C (1997) Quantitative analysis of macrobenthic soft-bottom assemblages in South Shetland waters. Polar Biol 17:393-400 
Saiz-Salinas JI, Ramos A, Munilla T, Rauschert M (1998) Changes in the biomass and dominant feeding mode of benthic assemblages with depth off Livingston Island (Antarctica). Polar Biol 19:424-428

Schewe I, Soltwedel T (2003) Benthic response to ice-edge-induced particle flux in the Arctic Ocean. Polar Biol 26:610-620

Smilauer P (1992) CanoDraw. User Guide v. 3.00. Environmental Change Research Centre, University College London, London

Smith CR, Mincks S, DeMaster DJ (2006) A synthesis of bentho-pelagic coupling on the Antarctic shelf: food banks, ecosystem inertia and global climate change. Deep Sea Res II 53:875-894

Ter Braak CJF (1988) CANOCO a FORTRAN programme for canonical community ordination by [partial] [detrended] [canonical] correspondence analysis, principal components analysis and redundancy analysis (version 2.1). Agricultural Mathematics Group, Wageningen

Ter Braak CJF (1990) Update notes: Canoco version 3.1. Agricultural Mathematics Group, Wageningen

Troncoso JS, Aldea C, Arnaud P, Ramos A, García F (2007) Quantitative analysis of softbottom molluscs in the Bellingshausen Sea and around Peter I Island. Polar Res 26(2):126134

Wentworth CK (1922) A scale of grade and class terms for clastic sediments. J Geol 30:377392

Wollenburg JE, Kuhnt W (2000) The response of benthic foraminifers to carbon flux and primary production in the Arctic Ocean. Mar Micropaleontol 40:189-231 